\title{
Global survey of rice breeders to investigate characteristics and willingness to adopt alternative breeding methods
}

Bert Lenaerts ${ }^{1,2,3}$, Bertrand C. Y. Collard ${ }^{4}$ and Matty Demont ${ }^{2^{*}}$

\begin{abstract}
Background: Despite the critical role rice breeders play to ensure food security, there is a lack of information regarding their current socio-economic characteristics, constraints and attitudes towards technology adoption. Some key concepts like budget, experience, local ecosystems, level of education and even main breeding method have hardly been surveyed in the past. This not only clouds any policy making regarding scientists in national agricultural research programmes, it also makes it difficult to assess the needs and problems local rice breeders face around the world.
\end{abstract}

Methods: A global online survey was conducted reaching 189 rice breeders from 51 rice-growing countries around the world. The questionnaire was structured according to an adoption framework we proposed from the literature. We specifically investigated their attitudes to adopting an alternative breeding method called rapid generation advance (RGA) (also known as single seed descent). To provide some historical perspective, we compare our results with those reported by Hargrove (Rice breeders in Asia: a ten-country survey of their backgrounds, attitudes, and use of genetic materials, 1978), the only published survey on rice breeders.

Results: Overall, rice breeders are highly educated and have a long experience with their main breeding method. However, a gender gap with respect to education seems to persist. Large variation in resources (staff, land and budget) was observed with a small number of resource-rich institutes and a large number of resource-poor institutes. Most rice breeders are focused on breeding for irrigated conditions. Most breeders have a relatively high degree of risk taking and time preference towards shorter breeding cycles. The majority of breeders are aware of RGA and its benefits with more than half having observed RGA in practice. Finally, breeders are confident in the RGA technique and estimate its resource savings to be substantial.

Conclusions: Breeders' willingness to adopt RGA was remarkably high. Surprisingly, adoption of RGA remains low ( $4 \%$ as main method). This may suggest that the benefits of using the RGA method still need to be further demonstrated in rice breeding. Our results could be useful to develop targeted extension material or interventions for implementing new technologies, which could be useful to high-level agricultural managers, international research centres and aid agencies.

Keywords: Rice breeding, Pedigree method, Rapid generation advance, Breeding cycle, Gender, Technology adoption

\footnotetext{
*Correspondence: m.demont@irri.org

${ }^{2}$ Agri-food Policy Platform, International Rice Research Institute (IRRI), Los

Baños, Philippines

Full list of author information is available at the end of the article
} 


\section{Background}

In the past 50 years, rice farming has already undergone a great transformation, of which a large part can be attributed to improved varieties. The first rice semidwarf varieties were developed and released in the 1960s and 1970s and had a dramatic impact on production [6, 14]. However, rice breeding is a slow and tedious process, although new technologies have cut the time needed to develop and test new varieties. Recently two challenges are appearing on the horizon. The first, and probably most daunting challenge, is the increasing demand for rice that will put pressure on rice breeding; rice production will need to increase to feed the global population in future [31]. There are many anticipated challenges to increase rice production in the twenty-first century, including decreasing land area devoted to agriculture, increased environmental pollution, and land degradation [5,20]. Climate change is also likely to adversely affect yield in the future [27]. This poses a dangerous mix of mutually reinforcing factors that will lead to a strong increase in demand. This increase will be especially strong in the developing world where not only poverty and population growth are high but also climate change is expected to hit hardest [22]. These factors will not only increase the general level of demand but accelerate the speed of increase as well. This means breeding methods need not only to deliver better rice varieties, but deliver them more quickly as well. These challenges require a drastic rethinking of current breeding methods to be able to meet future demands $[1,11,12]$.

In the past, International Agricultural Research Centres (IARCs), such as the International Rice Research Institute (IRRI), developed and disseminated a range of varieties and technologies needed by the highly diverse rice-growing world. However, during the last 10-20 years, the continuous development of new varieties and improvement of farming methods has been undertaken by National Agricultural Research and Extension Systems (NARES). Reduced funding to IARCs and an increasing reliance on local knowledge and expertise have made NARES partners indispensable in the development of new rice varieties. This trend is visible in the increased operational capability of many NARES partners [4] and IARCs' gradual shift from delivering finished varieties to providing only germplasm [14]. Unfortunately, despite a long and fruitful partnership with NARES breeders, little work has been reported about their characteristics. Some key concepts like budget, experience, local ecosystems, level of education and even main breeding method have hardly been surveyed in the past. This not only clouds any policy making regarding NARES scientists, it also makes it difficult to assess the needs and problems local rice breeders face around the world.
Despite the vital importance of rice breeding, there is almost a complete lack of information regarding socioeconomic status or current constraints of rice breeders and their currently used breeding methods. While many policy makers emphasise the need for new and innovating breeding methods, those same policy makers are left in the dark about the current status of breeding technology in the field. Following this, questions about, for example, institutional resources or educational background of rice breeders have long remained unanswered. Some key breeder characteristics were surveyed in the past by Hargrove [17], the only previous survey conducted on rice breeders. This study suffers some limitations as it only surveyed a small number of Asian breeders on a limited set of characteristics. The author himself points to the importance of agricultural scientists and the fact that little is known about them. Unfortunately, his study received little follow-up research.

Due to the anticipated future challenges of increasing rice production, a superior rice breeding method called rapid generation advance (RGA) was recently proposed for routine adoption for breeding of inbred rice varieties [10]. Rapid generation advance (RGA) has been used in many other plant breeding programmes for field crops [28] and has been described in many textbooks. Briefly, the method is used to speed up the process of line fixation (i.e. making lines genetically homozygous) in self-pollinated crops. Usually, this involves high-density planting of breeding populations (usually in a greenhouse) which causes plants to flower and set seed earlier compared to the field, and hence generations can be advanced more quickly. The main advantages of using RGA include quicker plant breeding, decreased costs for breeding programmes and institutes, and increased public benefits because new varieties may be available earlier than using other methods [23]. In essence, the RGA method is technically simple and requires considerably less resources compared to other rice breeding methods [10]. The cost reduction arises from: (a) significantly lower space (i.e. field space) requirements per generation; (b) drastically lower labour demand because no screening is required; and (c) saving materials and tools for data collection [24]. When combined, this could lead to a large decrease in breeding costs. Secondly, public benefits increase because varieties can be released earlier [26] - reducing "time to market"-and because-according to selection theory-RGA will increase the rate of genetic gain or rate of yield increase over time. Thirdly, labour can be more controlled over the year and the RGA method is highly flexible, which means it can be easily adapted to different, existing breeding programmes. Despite the successful implementation of RGA in other crops and a small number of empirical studies confirming its effectiveness, its 
use for rice breeding has been extremely limited $[15,18$, 24]. RGA was widely used at various times at IRRI and was recently adopted on a large scale for irrigated rice breeding at IRRI in order to increase rice breeding efficiency [10].

To fill the current knowledge gap about socio-economic factors about breeders, their methods and attitudes, we investigated the current status of rice breeding programmes and provide data about the global population of rice breeders using an extensive list of characteristics. To achieve this, we contextualised an adoption framework from the literature [13] to the case of plant breeding and conducted a global online survey of rice breeders to present some insights into rice breeders and their methods. We also specifically investigated their attitudes to adopting RGA instead of their current method. To provide some historical perspective, we compare our results with those reported by Hargrove [17], the only published survey on rice breeders.

\section{Methods \\ Adoption framework}

Over the years a variety of technology adoption frameworks has been developed in the context of farmers [29, 32]. More recently, attention has focused on the concept of willingness to adopt (WTA). In contrast to conventional adoption studies, studies on willingness to adopt look from an ex ante point of view (i.e. before adoption takes place) at the adoption of technology by farmers, or more accurately, to their stated willingness to adopt a certain technology. Farmers are given a scenario explaining all relevant characteristics of the new technology after which they are asked whether they are willing to adopt. In other words, their willingness to adopt is a stated, hypothetical decision conditional on the scenario given. In most cases, this stated willingness to adopt is seen as a binary (yes/no) choice $[2,8,16,25]$, but it can also be represented by a categorical or continuous variable, like a technology package [3] or the area to be cultivated with the new technology [7]. A willingness to adopt approach is especially useful when adoption is low.

Nonetheless, farm structures are not comparable to the large organisational structures in which rice breeding programmes are embedded. Unless they are operating under contract farming, farmers have full decision-making power over input use and production technology as they both manage and own the farm. Breeders in a breeding station, in contrast, often report to a breeding department head or head of the institute. Also, farms are either small-scale-often producing for subsistence-or businesses with a private profit-maximising goal. Institutes, on the other hand, operate on a larger scale and want to maximise profits (private sector) or social welfare (public sector). These organisational differences are most likely to influence the adoption process. Nevertheless, to date, no adoption studies exist that look specifically at the adoption process of new technologies within agricultural organisations, like breeding institutes or programmes.

To understand the adoption of a technology within an organisation, we followed guidelines from England et al. [13], who developed a framework for the adoption of information technology by health (care) organisations, which in turn was based on Rogers' [30] seminal work on adoption and diffusion of innovations. The authors apply innovation diffusion theory to identify variables that either influence the rate of adoption by organisations (an "organisation's readiness to adopt") or the rate at which a technology diffuses (the "technology's readiness to be adopted"). For this article, we are mainly interested in the former. According to England et al. [13], the three categories that influence an "organisation's readiness to adopt" are: (a) individual leader characteristics; (b) internal characteristics of the organisation, and (c) external characteristics of the organisation. In Fig. 1, we contextualise this framework to the case of plant breeding to study plant breeders' willingness to adopt new technologies.

Individual leader characteristics are influenced by personal characteristics, experience, perception of the technology, breeding mentality and operating style. Personal characteristics include age, gender and education while experience is understood as breeding experience and awareness about and/or observation of specific breeding technologies in the field. Perception can be measured as the credibility breeders attach to the scenario offered to them. Breeding mentality is captured in the number of generations it takes to fix a line and the number of years before yield trials can start. Operating style looks at breeders' preferences regarding cost, labour, time, risk and their innovativeness.

Internal characteristics of the organisation comprise freedom, resources, the ongoing breeding operations, the type of organisation and the job function. Freedom is determined by the possibility to implement and experiment with new techniques-called the "level of formalisation" by England et al. [13]. Resources are understood as the sum of land, budget, labour-both staff and seasonal-and specific facilities such as a greenhouse. Constraints to or abundance of one of these may influence a breeder's decision to adopt a specific breeding technology since breeding methods can differ substantially in resource use. Furthermore, factors related to their job as breeders might play a role, such as the length of their employment contract and their position in the institute's hierarchy. Given the duration of a standard breeding programme, having a permanent job employment contract might encourage breeders to take long-term decisions 


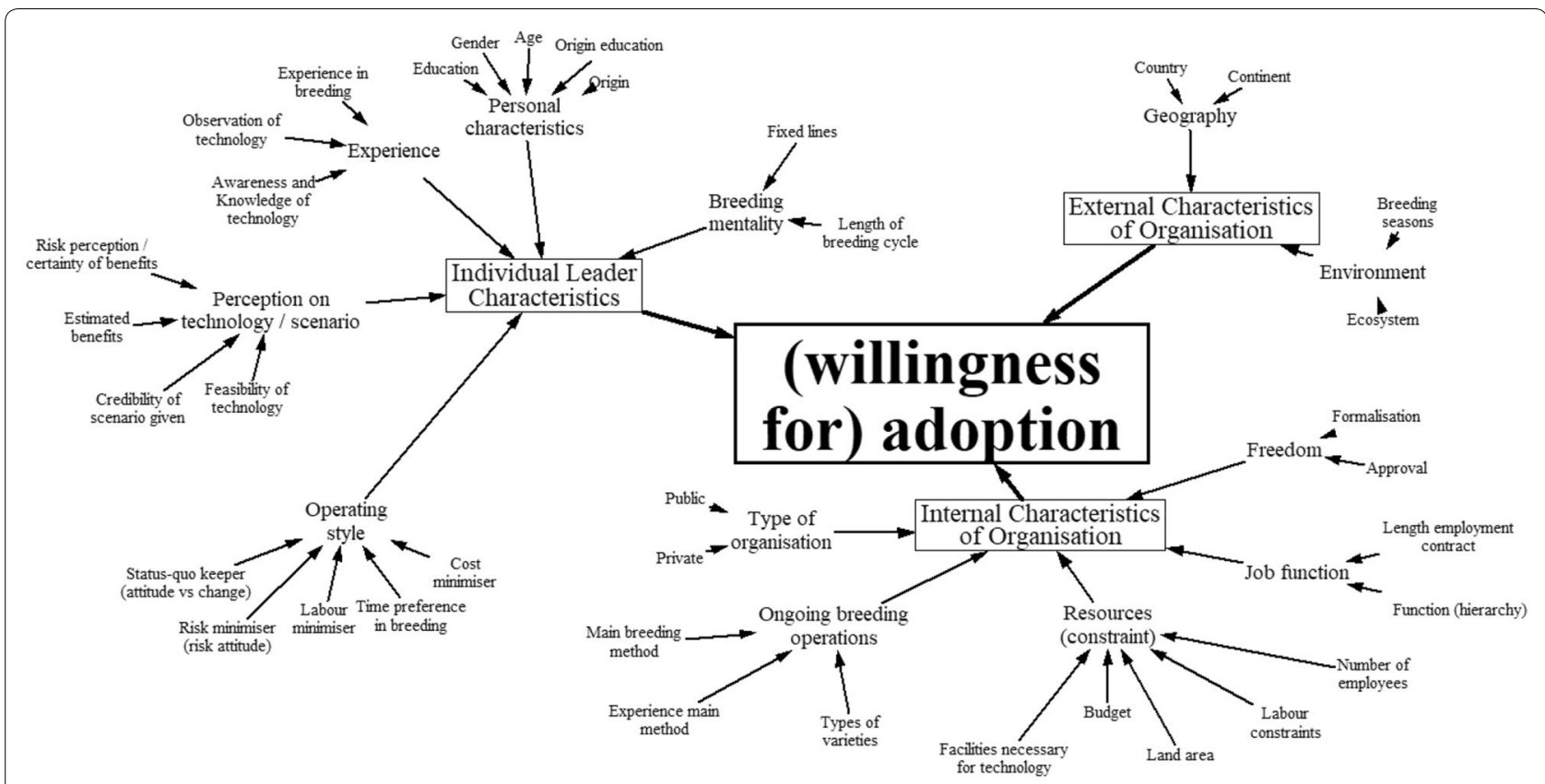

Fig. 1 Framework for the adoption of new technologies in plant breeding Source: England et al. [13], Rogers [30], Hall et al. [16], Mathijs [25], Blazy et al. [2], and expert elicitation from the International Rice Research Institute

like adopting a new breeding method. Lastly, the use of inbreds and/or hybrids along with the main breeding method and the public or private nature of the institute are factors of importance.

Finally, the external characteristics of the organisation are captured through the number of breeding seasons a year that can be conducted, the ecosystem and the geographic location of the institute.

\section{Survey}

A global online survey using Google Forms was conducted reaching 189 rice breeders from 51 rice-growing countries around the world. Our target population consisted of all types of rice breeders working at IARCs (excluding current IRRI breeders) or NARES institutes around the world. Only currently employed rice breeders were considered (i.e. recently retired breeders were excluded). Some rice breeders who were not actively involved in breeding line development (e.g. only involved in testing advanced lines obtained from elsewhere), and people considered to be molecular breeders or molecular geneticists were also excluded from the survey, because they were not routinely involved in core breeding operations. Our focus was on breeders worldwide although the interest was more on breeders from Asia, Africa and Latin America. Due to unavailability of Google services in China, very few Chinese breeders responded (by completing the survey as an email attachment).
Email addresses of rice breeders in the world were compiled from IRRI's global rice breeding network. Most current IRRI breeders, scientists, country office representatives and key members in the global rice breeding community were consulted to provide nominations. IRRI has an extensive global rice breeding network from ongoing programmes (e.g. International Network for the Genetic Evaluation of Rice, INGER and Temperate Rice Research Consortium, TRRC) or currently funded research programmes (e.g. stress tolerant rice for Africa and South Asia, STRASA). Hybrid breeders were also included using contacts of the IRRI-led Hybrid Rice Development Consortium (HRDC). Breeders from the Africa Rice Center (AfricaRice) and the International Center for Tropical Agriculture (CIAT) were contacted to provide nominations for Africa and Latin America, respectively. Recent participants of the annual IRRI rice breeding course (2011-2013) and visitors who were rice breeders were also included. Note that no sampling frame was used to ensure representativeness of the sample due to the limitation of not being able to reach all breeders.

An initial email was sent to 415 putative rice breeders from each country requesting them to nominate rice breeders that report to them, or who were colleagues. From this information, the target population of rice breeders was prepared. The list was subsequently refined several times to ensure all emails were currently active. For some nominations, a second alternative email address 
was also provided and used to invite participants for the survey. Overall, emails were sent to over 480 rice breeder contacts. The survey was designed to take approximately 15-20 min to complete. Participants were given the option to complete the survey anonymously (the majority of breeders chose to leave their name). However, this does not rule out any potential bias introduced by this non-anonymity. Randomly awarded prizes consisting of IRRI books and souvenirs and a report summarising results were offered as an incentive to complete the survey (for non-anonymous breeders only).

Potential participants-adding up to 315 breederswere contacted in several rounds through email on behalf of Dr. Bertrand Collard, Senior Scientist and irrigated rice breeder at IRRI at the time of the survey. After the initial email, two independent reminders were sent and an additional 36 people were contacted for the first time whose email address we received during the first survey round. A separate reminder for the breeders in Africa was sent by the Deputy Director General and Director of Research for Development at the Africa Rice Center. A transcript of the actual survey has been included in Additional file 1 .

\section{Results and discussion}

The global survey generated a total of 189 responses, leading to a satisfactory response rate of approximately $50 \%$. In this section, we give a general overview of breeder characteristics as displayed by our sample. For ease of reading, all variables are reported in summary tables while graphs are used to highlight some important results. All categorical variables are summarised as counts $(n)$. For the categorical variables whose categories sum up to 1, relative frequencies are also given (\%). For non-mutually exclusive categorical variables, relative frequencies are not meaningful due to overlapping categories and therefore not given. Means and standard deviations were used to summarise symmetric continuous variables, and medians and interquartile ranges for asymmetric continuous and ordinal variables, where the latter are derived from a Likert scale. For categorical and ordinal variables, levels were indicated in the second column. The number of non-missing observations is given between brackets. To assess the geographic representativeness of the sample, weighting adjustment was applied using the area of paddy rice harvested in 2015 . All non-geographic variables, with the exception of the asymmetric continuous variables, were very robust to weighing and did not change significantly. Therefore, the non-weighted variables are presented here. Although this does not rule out bias between more and less progressive breeders within each country, it does indicate that the more progressive countries are not overrepresented. Additional graphs can be found in Additional file 2.

This section includes an overview of some individual breeder characteristics and a discussion of both the internal and external characteristics of breeding organisations. We end with an outline of the surveyed attitudes towards and adoption of rapid generation advance.

\section{Individual breeder characteristics}

Table 1 reports a list of individual breeder characteristics, which can be grouped into personal characteristics, experience, perception towards RGA, operating style and breeding mentality. See Additional file 2: Table 1 for more information about the country of origin distribution for breeders and their highest degree obtained.

First of all, $78 \%$ of rice breeders in the survey were male. Looking at the gender gap in science across the developing world, this seems representative. The UNESCO Institute for Statistics (2015) reports the following female employment rates in R\&D: $22.6 \%$ for East Asia and the Pacific, $18.9 \%$ for South and West Asia, and $30.0 \%$ for Sub-Saharan Africa. Given these regions represent approximately three quarters of surveyed breeders (see further), 22\% of females participating in our survey seem representative. The ages of the rice breeders ranged from 28 to 73 with a mean of 45 years. This is slightly older than the average of 42 years reported by Hargrove [17]. The average age is quite different from the number of years in total breeding experience (mean of 17, range 1-50). In comparison, these numbers do not seem to have changed much since 1978 (mean of 14 years).

In our recent survey more than half of the breeders held a Ph.D. degree, while approximately one-third held a Master's degree. These numbers are not very different from Hargrove's [17] survey (Fig. 2). This might indicate the educational landscape might not have changed much over time. However, the location where those PhDs were obtained has changed. Almost 40 years ago, $65 \%$ of the PhDs among rice breeders were obtained in highly developed countries (i.e. Canada, the USA, Europe, Japan or Australia) while that number is now only $18 \%$. This seems consistent with the finding that the number of adults with a degree in higher education has been increasing in developing countries with a factor of approximately 2.5 between 1975 and 1990 [33]. In brief, although the distribution of degrees in higher education among rice breeders has not changed much, there does seem to be an increased capacity for tertiary education in rice-growing countries. Lastly, there seems to be a clear gender gap in higher education (Fig. 3). While a majority of males has a Ph.D. and a third only a master's degree, this balance is reversed for females. This is in line with the World Bank's observation that 
Table 1 Overview of individual rice breeder characteristics

\begin{tabular}{|c|c|c|c|}
\hline & Level & All & \\
\hline \multicolumn{4}{|l|}{ Personal characteristics } \\
\hline Age (years) (189 obs.), mean (sd) & & 45.16 & $(9.52)$ \\
\hline \multirow[t]{2}{*}{ Gender (189 obs.), n (\%) } & Male & 148 & $(78 \%)$ \\
\hline & Female & 41 & $(22 \%)$ \\
\hline \multirow[t]{3}{*}{ Degree (187 obs.), $n$ (\%) } & Bachelor's degree & 8 & $(4 \%)$ \\
\hline & Master's degree & 67 & $(36 \%)$ \\
\hline & Ph.D. & 112 & $(60 \%)$ \\
\hline \multicolumn{4}{|l|}{ Experience } \\
\hline Awareness RGA (189 obs.), n (\%) & & 163 & $(86 \%)$ \\
\hline Awareness of benefits RGA (189 obs.), $n$ (\%) & & 158 & $(84 \%)$ \\
\hline Experience breeding (years) (189 obs.), mean (sd) & & 16.86 & $(10.02)$ \\
\hline Observation RGA (189 obs.), n (\%) & & 112 & $(59 \%)$ \\
\hline \multirow[t]{3}{*}{ Location of observation of RGA (91 obs.), $n$} & Observed RGA at IARC & 64 & \\
\hline & Observed RGA at NARES & 36 & \\
\hline & Observed RGA at private institute & 4 & \\
\hline \multicolumn{4}{|l|}{ Perception towards RGA } \\
\hline Percentage reduction in labour estimated from RGA (\%) (167 obs.), mean (sd) & & 43.16 & $(18.58)$ \\
\hline Percentage reduction in land estimated from RGA (\%) (171 obs.), mean (sd) & & 55.62 & $(21.09)$ \\
\hline Reduction time estimated from RGA (years) (114 obs.), mean (sd) & & 2.39 & $(1.13)$ \\
\hline Certainty of benefits RGA (185 obs.), median [IQR] & 1-not certain, 7-very certain & 5.00 & {$[4.00,6.00]$} \\
\hline Credibility benefits RGA (185obs.), median [IQR] & 1-not credible, 7-very credible & 6.00 & {$[5.00,7.00]$} \\
\hline Feasibility RGA method (184 obs.), median [IQR] & 1-not feasible, 7—very feasible & 5.00 & {$[5.00,7.00]$} \\
\hline \multicolumn{4}{|l|}{ Operating style } \\
\hline Cost minimiser (189 obs.), $n$ (\%) & & 134 & $(71 \%)$ \\
\hline Labour minimiser (189 obs.), $n$ (\%) & & 144 & $(76 \%)$ \\
\hline Actively looking for improvements (189 obs.), $n$ (\%) & & 188 & $(99 \%)$ \\
\hline Risk attitude (189 obs.), median [IQR] & 1-avoid risk, 7—like taking risks & 5.00 & {$[4.00,6.00]$} \\
\hline Time preference (breeding cycle as obstacle) (189 obs.), median [IQR] & 1-not an obstacle, 7-severe obstacle & 5.00 & {$[3.00,6.00]$} \\
\hline \multicolumn{4}{|l|}{ Breeding mentality } \\
\hline Time needed for fixed lines (crossing) (number of generations) (182 obs.), mean (sd) & & 7.07 & $(1.79)$ \\
\hline Time needed for fixed lines (trials) (number of generations) (183 obs.), mean (sd) & & 6.34 & $(1.07)$ \\
\hline Time needed before AYT testing (years) (183 obs.), mean (sd) & & 2.49 & $(1.07)$ \\
\hline
\end{tabular}

Sample size is 189 observations

$I Q R$ interquartile range, $A Y T$ advanced-stage yield trial

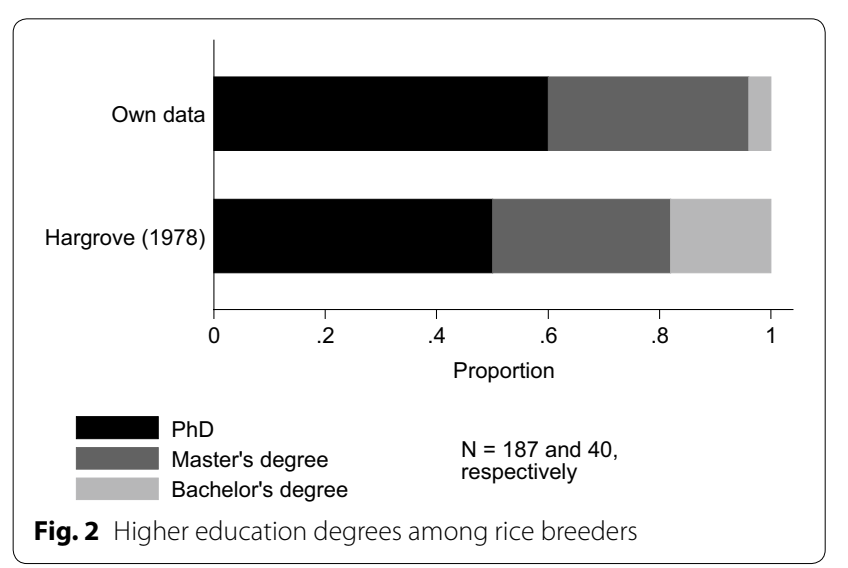

the highest gender gaps exist in South Asia, the Middle East and Sub-Saharan Africa-which account for $80 \%$ of surveyed breeders [33]. Despite the lack of historical comparison in the rice breeding sector, it is safe to say that improved gender equality in higher education is still a priority in many rice-growing countries.

Since breeding is a relatively slow process, timing and breeders' perceptions regarding this point are crucially important. To the best of our knowledge, our study is the first one that provides insights into the attitudes of rice breeders regarding breeding cycles (i.e. time from "cross to cross"). Additional file 2: Fig. 2 compares perceptions of time regarding breeding in more detail. We observe that most breeders regard five generations as 


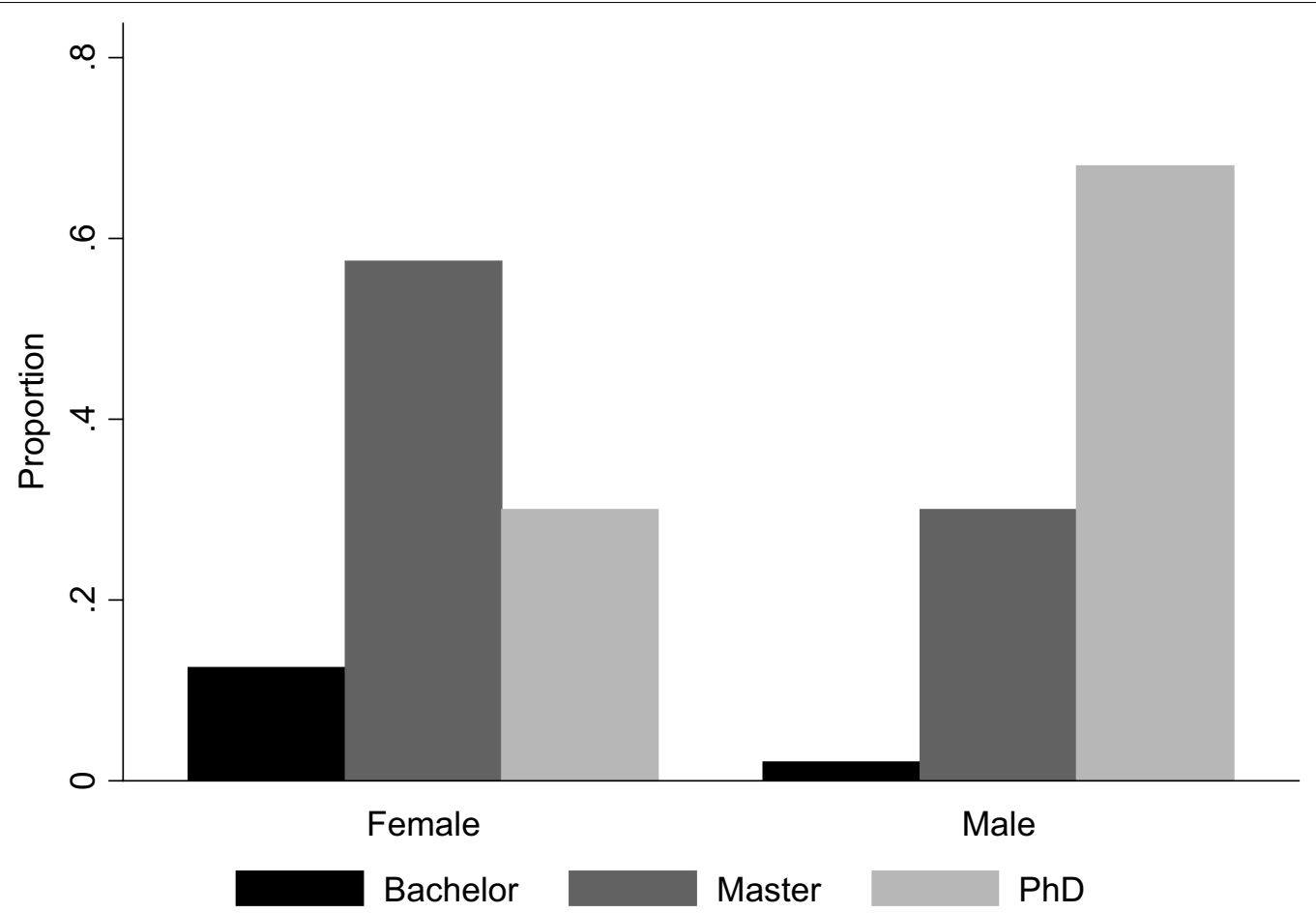

Fig. 3 Higher education of rice breeders by gender

the absolute minimum time period required to fix lines, both for trials and crossing. This is consistent with theory but surprising because our observations often noted rice breeders who test lines at advanced generations (F10 or beyond) which we believe is unnecessary. Using RGA, breeding lines can easily be fixed in 1-1.5 years, assuming that at least three generations can be completed within 12 months through the use of a greenhouse. The perceived time needed to adequately test elite breeding lines in advanced-stage yield trials before crossing can take place, is considered to be about 2-3 years for the majority of breeders. However, some authors advocate the need for shorter breeding cycles and so the time required for testing in advancedstage trials could be reduced [1]. In any case, reducing the length of the breeding cycle is considered to be the simplest way to increase the rate of genetic gain.

Regarding operating style, the majority of rice breeders identify themselves as labour and cost minimisers. In fact, hardly any breeder indicated he or she wanted to actively keep the status quo with regard to their breeding method. We also observed that breeders have a relatively high degree of risk taking and see the length of breeding cycle as an obstacle for improving farmers' livelihoods (time preference; median of 5 on 7 -point scale). The latter two factors can be important in determining breeder's willingness to adopt specific new breeding methods, like RGA.

We also surveyed breeders' perception towards and experience with the RGA method. We discovered that awareness about RGA is high, both for the method in general as for the benefits it can generate ( $>80 \%)$. Observation of the RGA method conducted in the field was lower, but still more than half of all breeders had seen the method used before. The majority of breeders observed RGA at an IARC. Most breeders seem confident in the RGA breeding technique; the feasibility of the method and the certainty of the benefits get a median of 5 on a 7 -point scale, and the credibility of the projected benefits for the IRRI case even gets a 6 (also, out of 7 points). Breeders also expect to save a significant amount of labour (43\%), land (56\%) and time (2.4 years). This shows that breeders in general have a very favourable view towards RGA and are well aware of its potential.

\section{Internal characteristics of organisation}

Table 2 reports a list of internal characteristics of the organisation, which can be grouped into type of organisation, breeding operations, job function, freedom and resources.

Public breeding institutes dominate as only $6 \%$ of surveyed breeders are active in a private breeding station. 
Table 2 Overview of internal characteristics of rice breeding organisations

\begin{tabular}{|c|c|c|c|}
\hline & Level & All & \\
\hline \multicolumn{4}{|l|}{ Type of organisation } \\
\hline \multicolumn{2}{|l|}{ Private institute (189 obs.), n (\%) } & 11 & $(6 \%)$ \\
\hline \multicolumn{4}{|l|}{ Breeding operations } \\
\hline \multirow[t]{4}{*}{ Main method (188 obs.), n (\%) } & Bulk & 10 & $(5 \%)$ \\
\hline & Combination & 7 & $(4 \%)$ \\
\hline & Pedigree & 147 & $(78 \%)$ \\
\hline & Other & 24 & $(13 \%)$ \\
\hline \multirow[t]{3}{*}{ Varieties (188 obs.), $n$ (\%) } & Hybrids only & 13 & $(7 \%)$ \\
\hline & Inbreds only & 130 & $(69 \%)$ \\
\hline & Inbreds and Hybrids & 45 & $(24 \%)$ \\
\hline \multicolumn{2}{|l|}{ Experience main method (years) (189 obs.), mean (sd) } & 13.93 & $(9.43)$ \\
\hline \multicolumn{4}{|l|}{ Job function } \\
\hline \multicolumn{2}{|l|}{ Permanent employment contract (189 obs.), n (\%) } & 168 & $(89 \%)$ \\
\hline \multirow[t]{3}{*}{ Hierarchy (177 obs.), n (\%) } & Head of department & 65 & $(37 \%)$ \\
\hline & Report directly to head of department & 100 & $(56 \%)$ \\
\hline & Report indirectly to head of department & 12 & $(7 \%)$ \\
\hline \multicolumn{4}{|l|}{ Freedom } \\
\hline \multicolumn{2}{|l|}{ Opportunities for new techniques (189 obs.), n (\%) } & 175 & $(93 \%)$ \\
\hline \multicolumn{2}{|l|}{ Permission to adopt RGA (153 obs.), n (\%) } & 149 & $(97 \%)$ \\
\hline \multicolumn{4}{|l|}{ Resources } \\
\hline \multirow[t]{8}{*}{ Timing labour constraint (185obs.), $n$} & Flowering & 20 & \\
\hline & Harvesting & 135 & \\
\hline & Land preparation & 52 & \\
\hline & Post-harvest & 67 & \\
\hline & Seedling nursery & 46 & \\
\hline & Transplanting & 128 & \\
\hline & Vegetative stage & 21 & \\
\hline & Never & 13 & \\
\hline Severity labour constraint (189 obs.), median [IQR] & 1-not severe, 7-prohibiting operations & 4.00 & {$[3.00,6.00]$} \\
\hline \multicolumn{2}{|l|}{ Staff institute (168 obs.), median [IQR] } & 100.00 & {$[27.50,355.00]$} \\
\hline \multicolumn{2}{|l|}{ Staff department (173 obs.), median [IQR] } & 17.00 & {$[10.00,40.00]$} \\
\hline \multicolumn{2}{|l|}{ Staff team (174 obs.), median [IQR] } & 6.00 & {$[5.00,10.00]$} \\
\hline \multicolumn{2}{|l|}{ Labour workers harvesting (174 obs.), median [IQR] } & 10.00 & {$[5.00,20.00]$} \\
\hline \multicolumn{2}{|l|}{ Labour workers seedling/transplanting (170 obs.), median [IQR] } & 10.00 & {$[5.00,20.00]$} \\
\hline \multicolumn{2}{|l|}{ Problems in cash flow (176 obs.), n (\%) } & 115 & $(0.65)$ \\
\hline \multicolumn{2}{|l|}{ Budget size (10,000 US\$) (141obs.), median [IQR] } & 2.56 & {$[1.00,12.72]$} \\
\hline \multirow[t]{3}{*}{ Likelihood budget cut (152 obs.), n (\%) } & Likely & 53 & $(35 \%)$ \\
\hline & Possibly & 71 & $(47 \%)$ \\
\hline & Not likely & 28 & $(18 \%)$ \\
\hline \multicolumn{2}{|l|}{ Land available (ha) (171 obs.), median [IQR] } & 3.00 & {$[1.50,6.00]$} \\
\hline \multicolumn{2}{|l|}{ Greenhouse present (189 obs.), n (\%) } & 130 & $(69 \%)$ \\
\hline
\end{tabular}

Sample size is 189 observations

$I Q R$ interquartile range

This reflects that the majority of rice breeding currently occurs in the public sector which is consistent with the prevalence of inbred varieties, although hybrid rice is common in some countries like China and gaining popularity in other countries. Hybrid varieties are usually produced by private companies, due to the requirement to purchase seeds for every season. Looking at the type of varieties bred, almost $70 \%$ of breeders use inbreds exclusively, and less than $10 \%$ work on hybrid rice. However, the number of breeders working on hybrid rice 

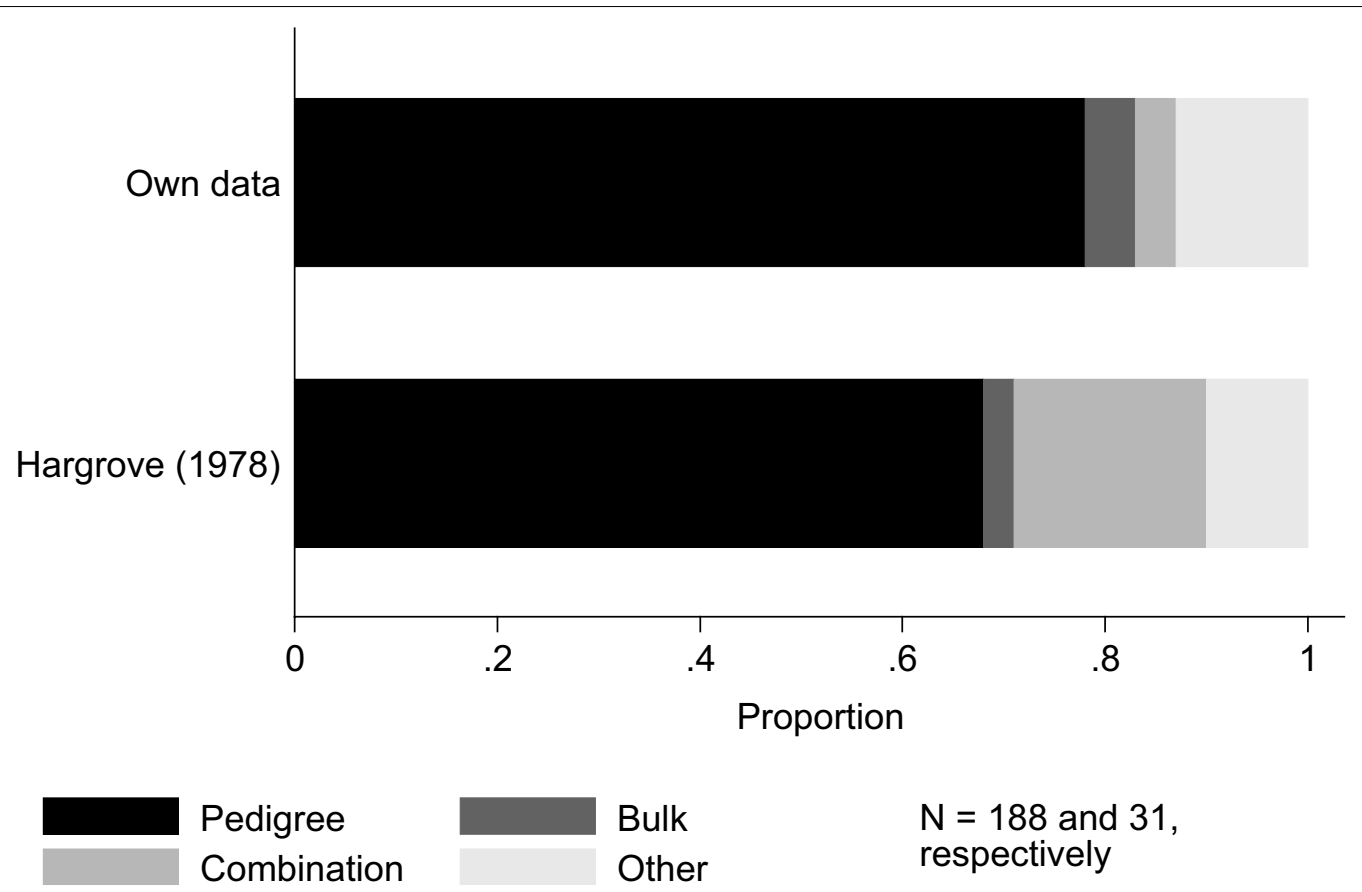

$\mathrm{N}=188$ and 31,
respectively

Fig. 4 Overview of rice breeding methods used

would have been higher if a larger sample from China was obtained.

Regarding breeding methods, the classic pedigree method is still by far the most common breeding method; almost $80 \%$ of breeders still use it as their main breeding method based on our results (Fig. 4). This method was widely popularised as the most effective rice breeding method at IRRI during the 1970s and 1980s [19, 21]. Comparing with Hargrove [17], we see this number has not changed much over time. This is an interesting result as the classical pedigree method has been used for many decades. Adding to this, breeders' experience with their main breeding technique (mean of 14, range of 1-50) is very close to breeders' total experience (mean of 17 , range of 1-50; see also Additional file 2: Fig. 1). This might indicate that breeders in general do not shift to another breeding method easily.

In the agricultural science literature, much attention goes to farmers and how their characteristics influence adoption of technologies. However, farm structures are not comparable to the large organisational structures displayed by breeding institutes. These organisational differences are most likely to influence the adoption process. In our survey, we see that breeders still enjoy a relatively high degree of freedom as the large majority have a permanent employment contract (89\%), expect to get permission to adopt RGA (97\%) and have opportunities to experiment with and implement new breeding techniques (93\%). About one-third of respondents are heads of departments and slightly more than half report directly to the head of department. These high percentages might point to the fact that breeders themselves enjoy a relatively high degree of decision-making power.

As mentioned above, NARES are increasing their capacity in performing their own breeding operations. Nevertheless, resource constraints remain a key problem for many breeders including those at IARC research centres and even private breeding companies. A greenhouse or screenhouse facility (which is generally recommended for the RGA procedure) is relatively common (69\%) but so are problems in cash flows: $65 \%$ of breeders indicated there are times of the year where their budget is insufficient. Thus, breeding methods requiring a greenhouse might not be a problem as long as they do not introduce (unforeseen) additional cash expenses during the year. Other important resources are labour, budget and area of land available. Starting with the first, the median number of staff depends on the level of aggregation: institutes employ around 100 staff members, departments about 17 and breeding teams around 6 . It is important to note though that the variation in staff members is much larger for institutes than for the lower levels (departments and teams). While a large number of institutes employ relatively low levels of staff, there is a non-trivial number that employs 1000 or more staff members (see Additional file 2: Fig. 3). This large variability is likely to inflate the 
mean somewhat, and therefore the median might be a better indicator of the overall employment levels of staff across breeding institutes. Additionally, although clearly specified, the inclusion of seasonal labourers might be an explanation for these rather high levels of staff employment for certain institutes. Next, during labour peaks (i.e. harvesting and seeding/transplanting), a median number of 10 labour workers are employed per breeding team.

Other important resources in the breeding process are budget and land available. Looking at the median, each breeding institute uses around 3.00 ha of land and US\$ 25,609 . Again, these variables portray a very high variability: the area of land ranges between $50 \mathrm{~m}^{2}$ and 267 ha (13 breeders dispose of an area over 20 ha $)^{1}$ and the available budget ranges between US\$ 47 and US\$3,350,000 (14 breeders dispose of budgets over US $\$ 400,000)^{2}$ (see Additional file 2: Fig. 4). Despite the presence of these remarkably high values, there is a clear concentration of institutes at relatively low values (indicated by the median being closer to the 25 th than the 75 th percentile). Thus, although the total number of resources seems quite abundant, this impression is biased due to the presence of some relatively resource-rich institutes in the survey. Many smaller institutes may actually lack the necessary resources to innovate their breeding operations and perform their current breeding goals. Approximately half of the breeders even think a budget cut within the next 5 years is possible while $35 \%$ think it is likely. Lastly, gender also plays a role in determining budgets. Females who are head of their department dispose of only one-third of the budget their male counterparts dispose of (Fig. 5). It is interesting to note that this gender gap does not seem to hold at a lower hierarchical level.

\section{External characteristics of organisation}

Table 3 reports a list of external characteristics of the organisation, which can be grouped into environment and geography. We observed that almost $80 \%$ of breeders work under irrigated conditions, which is half of all ecosystems reported by Hargrove [17]. Approximately $30 \%$ of ecosystems reported by Hargrove [17] are rainfed and $17 \%$ upland. These numbers are consistent with Hargrove's [17] survey (Fig. 6). Additionally, approximately $12 \%$ of breeders focus on temperate environments, and

\footnotetext{
${ }^{1}$ Under normal circumstances, $50 \mathrm{~m}^{2}$ is inadequate as a breeding area. In this case, the breeder in question uses his/her breeding area solely for experimenting with rice under conditions that are generally unfavourable to rice.

${ }^{2}$ Under normal circumstances, US\$ 47 is inadequate as a breeding budget. In this case, the small dollar value might be due to a serious devaluation of the Venezuelan bolivar.
}

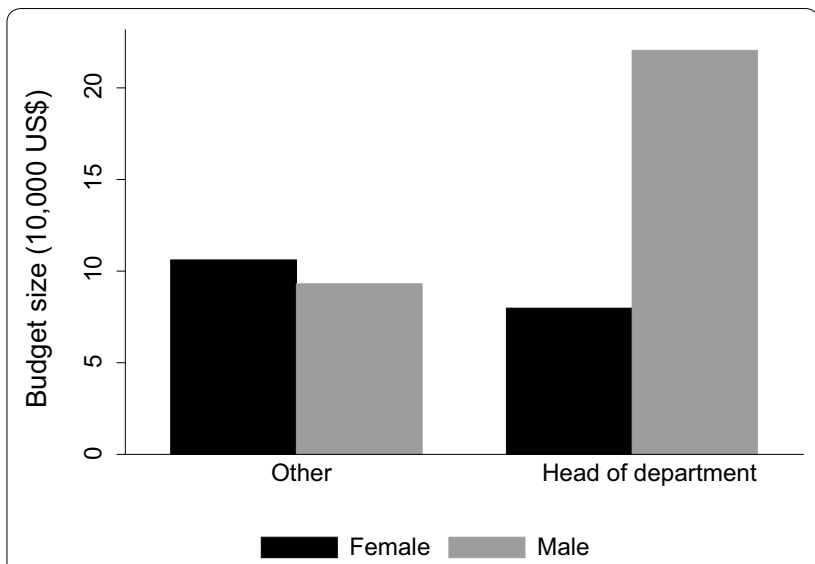

Fig. 5 Comparison of rice breeders' budgets among heads of department by gender

$29 \%$ focus on coastal, flood-prone or both regions. The average number of seasons per year was 1.6.

Our focus was on breeders worldwide although, as can be expected, most rice breeders are active in breeding stations in Asia (65\%) with $15 \%$ of breeders active in Africa and $12 \%$ in South America. Rice production in Europe is extremely limited; only Russian breeders responded to our survey (other countries where rice is grown include Italy, Spain, Greece, Portugal, France, Romania, Bulgaria and Hungary). Unfortunately, the IRRI network in Europe was limited because of IRRI's few collaborations in rice breeding with European countries.

\section{Adoption of and willingness to adopt (WTA) rapid generation advance}

Table 4 summarises the current adoption status of RGA among breeders and their stated willingness to adopt RGA, as well as underlying reasons for those decisions.

To survey willingness to adopt (WTA), we presented breeders with a brief scenario of RGA operations at the International Rice Research Institute (IRRI). Afterwards we asked breeders whether they were willing to adopt RGA, if they had not done so already. We already noted that breeders showed a very favourable view towards RGA. Looking at Table 4, we see this was reflected in a high level of WTA. Of all breeders who had not yet adopted RGA as their main method, approximately $75 \%$ were willing to adopt RGA as their secondary or main method; only $10 \%$ did not want to adopt RGA in any way, not even for testing (Fig. 7). This figure remains the same if we look only at those who had not yet adopted RGA as secondary or main method. Both the positive view and high WTA are in sharp contrast with the low degree of adoption. Only a quarter used RGA as a secondary method and approximately $4 \%$ as their main breeding 
Table 3 Overview of external characteristics of rice breeding organisations

\begin{tabular}{llll}
\hline & Level & All & \\
\hline Environment & & & \\
Ecosystem (188 obs.), $n$ & Coastal & 25 & \\
& Deepwater & 12 & \\
& Flood prone & 30 & \\
& Irrigated & 147 & \\
& Rainfed & 86 & \\
& Temperate & 23 & \\
& Upland & 50 & \\
Seasons per year (189 obs.), mean (sd) & & 1.62 & $(0.56)$ \\
Geography & & & \\
Origin (location) institute (189 obs.), $n$ (\%) & Asia & 123 & $(65 \%)$ \\
& Africa & 28 & $(15 \%)$ \\
& South America & 23 & $(12 \%)$ \\
& North America & 8 & $(4 \%)$ \\
& Europe & 2 & $(1 \%)$ \\
& Middle East & 5 & $(3 \%)$ \\
\hline
\end{tabular}

Sample size is 189 observations

method. The use of a secondary method was interesting (i.e. that breeders use multiple methods) and could have been due to the requirement to develop some populations for research purposes (e.g. genetic analysis) rather than actual breeding. It should also be noted that in practice, it is complicated to introduce large-scale changes to breeding operations.

When asked why people were not willing to adopt, the lack of a greenhouse and no certainty about the benefits were given most often in reply. Note that the low number of responses was due to the fact that only 19 breeders were not willing to adopt RGA in any way (excluding main adopters). For those willing to adopt, the lack of a greenhouse and lack of money were seen as the biggest obstacles. For these people, time savings and reductions in cost, labour and land were all given as important reasons for adopting RGA. Among breeders reporting only one obstacle to adopting RGA, a lack of greenhouse infrastructure was given in more than half of the cases (see Additional file 1). When asked for the use of saved resources, extra screening was mentioned as the most common answer in our survey, but also extra crosses, yield trials at multiple locations and larger yield trials were reported. Regarding crosses, it is interesting to note that some previous research suggests that making extra crosses does not improve breeding efficiency [34]. This could point to Cleveland's [9] observation that plant breeding science is both a biophysical and social construction of reality. Only a small minority would not use the saved resources at all. These observations led us to hypothesise that these reasons were based on subjective

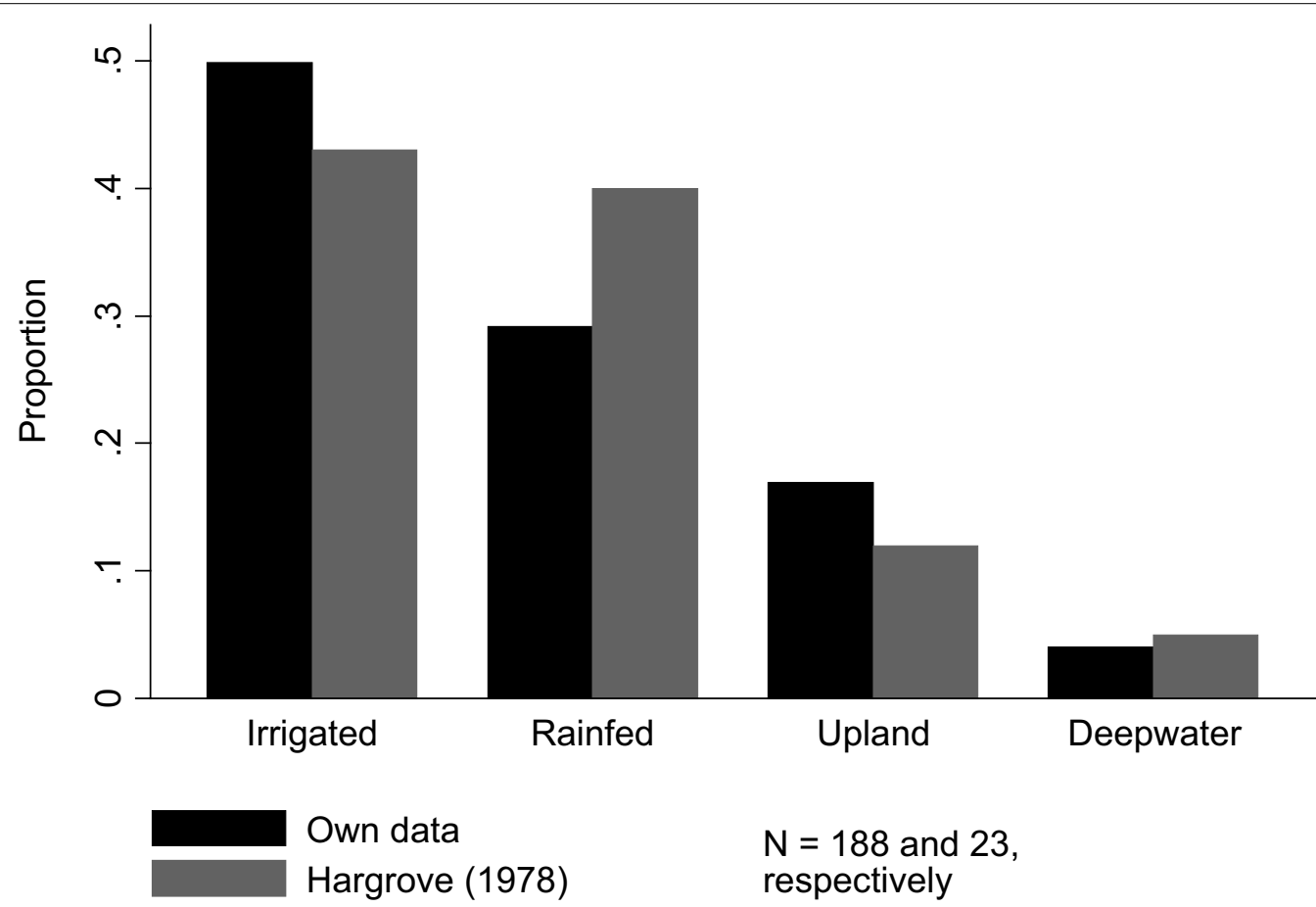

Fig. 6 Proportion of ecosystems in which rice breeders are operating 
Table 4 Rice breeders' adoption status/intentions and underlying reasons regarding RGA

\begin{tabular}{|c|c|c|c|}
\hline & Level & All & \\
\hline \multirow[t]{10}{*}{ Adoption and Willingness to Adopt (WTA) (184 obs.), n (\%) } & No adoption, but WTA for testing & 28 & $(15 \%)$ \\
\hline & No adoption, but WTA to secondary method & 51 & $(28 \%)$ \\
\hline & No adoption, but WTA to main method & 23 & $(13 \%)$ \\
\hline & No adoption nor WTA & 5 & $(3 \%)$ \\
\hline & Adoption for testing, but WTA to secondary method & 18 & $(10 \%)$ \\
\hline & Adoption for testing, but WTA to main method & 6 & $(3 \%)$ \\
\hline & Adoption for testing, but no further WTA & 2 & $(1 \%)$ \\
\hline & Adoption as secondary method, but WTA to main method & 31 & $(17 \%)$ \\
\hline & Adoption as secondary method, but no further WTA & 12 & $(7 \%)$ \\
\hline & Adoption as main method & 8 & $(4 \%)$ \\
\hline \multirow[t]{7}{*}{ Reasons for willingness to adopt RGA (157 obs.), $n$} & Time saving & 140 & \\
\hline & Cost reduction & 120 & \\
\hline & Labour reduction & 120 & \\
\hline & Land reduction & 118 & \\
\hline & Genetic gain & 57 & \\
\hline & Public benefits & 27 & \\
\hline & Subsidies & 3 & \\
\hline \multirow[t]{5}{*}{ Destination of resource savings when willing to adopt RGA (157 obs.), n } & Extra screening & 89 & \\
\hline & Extra crosses & 75 & \\
\hline & Multilocation yield trails (MLYT) & 72 & \\
\hline & Larger yield trials & 51 & \\
\hline & Nothing & 4 & \\
\hline \multirow[t]{5}{*}{ Reasons for non-willingness to adopt RGA (19 obs.), $n$} & No greenhouse/screenhouse & 6 & \\
\hline & Lack of money & 2 & \\
\hline & Need approval from superiors & 2 & \\
\hline & Not enough labour available & 3 & \\
\hline & Not certain about benefits & 6 & \\
\hline \multirow[t]{5}{*}{ Obstacles when willing to adopt RGA (157 obs.), $n$} & No greenhouse/screenhouse & 109 & \\
\hline & Lack of money & 67 & \\
\hline & Not enough labour available & 24 & \\
\hline & Need approval from superiors & 32 & \\
\hline & Not certain about benefits & 19 & \\
\hline
\end{tabular}

Sample size is 189 observations in total, 157 for those willing to adopt and 19 for those not willing

views rather than evidence and that research involving the optimisation of rice breeding programmes is a research gap that warrants further investigation.

Interestingly, no breeder commented on the possible use of DNA markers; however this was not listed as an option (i.e. but it could have been listed as 'other'). We deliberately did not include survey questions about the use of DNA marker technology because in our experience, the current use of molecular breeding in routine rice breeding is still very low in most countries. Furthermore, including additional questions to survey this topic would have greatly increased the length of the survey and would have greatly widened the scope of our study, and may have diminished our main objectives. It is worth noting that molecular breeding schemes such as markerassisted selection or genomic selection can be implemented in any breeding scheme, but may specifically provide further improvements in efficiency when incorporated in a RGA-based breeding scheme [10].

\section{Conclusion}

In this article, we have displayed a range of characteristics describing breeders' characteristics, attitudes and adoption behaviour towards new breeding technologies. To cover the entire spectrum of characteristics, we looked at individual breeder characteristics, as well as the internal and external characteristics of the organisation. This way we have presented a relatively unique insight 


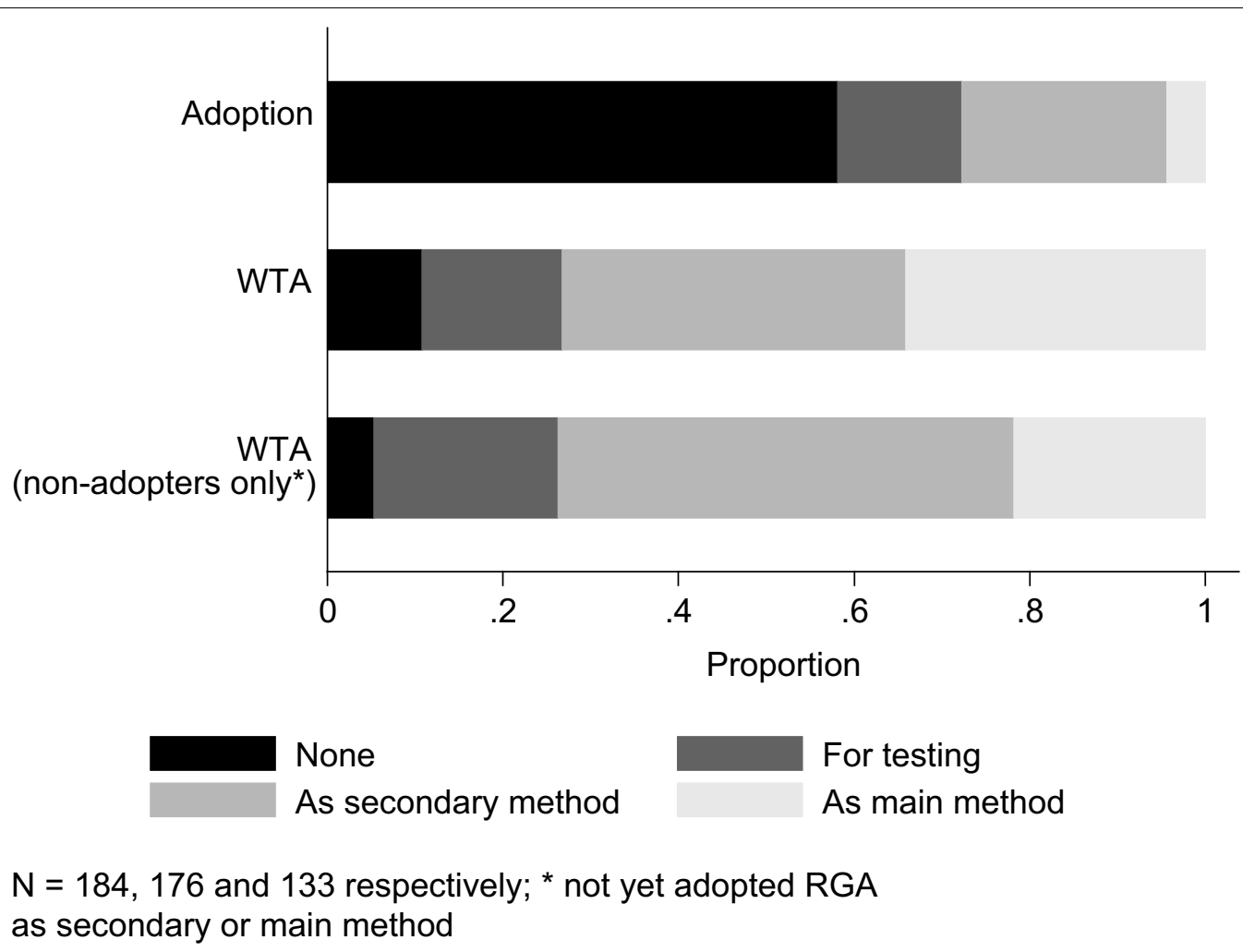

Fig. 7 Rice breeders' adoption status/willingness to adopt RGA

into the population of rice breeders worldwide. Overall, rice breeders are highly educated and have a long experience with their main method. A clear gender gap regarding education seems present. The variability in resources (staff, land and budget) is particularly large and makes it hard to assess to overall operational capacity of rice breeders worldwide. While some institutes clearly have access to large resources, these need to be considered exceptions given the large number of resource-poor institutes. Most breeders are active in irrigated conditions. Contrary to expectations, breeders expressed a relatively high degree of operational freedom and relying on their stated operating styles, rice breeders seem relative open to innovation. Our results permitted us to characterise global rice breeders, especially in Asia, Africa and South America. To the best of our knowledge, this was not done before and allows us to lay down a reference about the characteristics and adoption behaviour of rice breeders. As a baseline, it will be crucial for comparisons in the future. By identifying the global rice breeder population, we have made it visible for the first time. Where possible, we compared our results to previous ones and overall our findings seem consistent and do not differ much for the variables reported.

Secondly, we looked at several characteristics related to rapid generation advance. Overall, our findings indicated a positive perception towards rapid generation advance (RGA). Most breeders have an operating style with a relatively high degree of risk taking and time preference, greenhouses were not uncommon (69\%) and almost all breeders expected to get permission to adopt RGA (97\%). Approximately $85 \%$ of breeders are aware of RGA and its benefits. More than half of breeders have observed the actual use of RGA. Furthermore, breeders are confident in the RGA technique (high feasibility, certainty and credibility of benefits) and estimate its resource savings to be substantial. As a consequence, breeders' willingness to adopt RGA was remarkably high: only $10 \%$ did not want to adopt RGA in any way, not even for testing. Surprisingly, adoption of RGA remains low ( $4 \%$ as main method) while the classical well-known pedigree breeding method is still the most common breeding method. Possible reasons are lack of greenhouse facilities, uncertainty about the 
benefits among breeders and insufficient operational budgets. Our results could be useful to develop targeted extension material or interventions for implementing new technologies, which could be useful to high-level agricultural managers, international research centres and aid agencies. These technologies could have tremendous impacts in terms of accelerating the delivery of rice varieties that are targeted to the needs of rice farming communities and consumers around the world.

\section{Additional files}

Additional file 1. Transcript of the actual survey.

Additional file 2. Additional tables and figures from the same dataset discussed in this article.

\section{Authors' contributions}

$B L$ developed ideas and wrote the manuscript with inputs from $B C$ and $M D$. $\mathrm{BL}, \mathrm{BC}$ and $\mathrm{MD}$ developed and coordinated the survey. $\mathrm{BC}$ drafted sections about the use of RGA. BL and MD analysed the results. All authors read and approved the final manuscript.

\section{Author details}

${ }^{1}$ Centre for Environmental Sciences, UHasselt, Hasselt, Belgium. ${ }^{2}$ Agri-food Policy Platform, International Rice Research Institute (IRRI), Los Baños, Philippines. ${ }^{3}$ Department of Earth and Environmental Sciences, KU Leuven, Leuven, Belgium. ${ }^{4}$ Plant Breeding Platform, International Rice Research Institute (IRRI), Los Baños, Philippines.

\section{Acknowledgements}

We thank all of the respondents for their time. We also thank many colleagues and rice breeding contacts (especially Drs. Md. Rafiqul Islam, Tsutomu Ishimaru, Jeom-Sig Lee, Ed Redona, Shaobeng Peng, Changrong Ye, Fangmig Xie, Surapong Sarkarung, S. L. Krishnamurthy, Flavio Breseghello, Mohd Solihen Bin Jama, Marco Wopereiss) for providing additional names and contact details within specific countries or regions to be included in the survey. The authors would like to acknowledge Dr. Yann de Mey for his excellent research support.

\section{Competing interests}

The authors declare that they have no competing interests.

\section{Availability of data and materials}

The dataset generated and analysed during the current study is not publicly available due to pending research articles relying on the same dataset but is available from the corresponding author upon request.

\section{Consent for publication}

Not applicable.

\section{Ethics approval and consent to participate}

There is no institutional review board at IRRI at this time. However, this work has been reviewed and approved by the Agri-food Policy Platform Leader and the Deputy Director General for Research through an internal review process. All participants in this study gave informed oral consent prior to the survey interview and had the option to terminate the interview at any point. No minors were directly interviewed during this study. All datasets collected by the Agri-food Policy Platform at IRRI are ultimately uploaded and made available for public use. However, it is our policy to first make datasets anonymous prior to uploading. This is done by removing all identifying information within the dataset, including: name, email, telephone number, street address, and GPS coordinates. These measures are done with the approval of the Chief Information Officer of IRRI.

\section{Funding}

Financing was provided by the Bill and Melinda Gates Foundation (BMGF) Transforming Rice Breeding (TRB) Project [Grant No. OPP1076488] and the CGIAR Research Program on Rice.

\section{Publisher's Note}

Springer Nature remains neutral with regard to jurisdictional claims in published maps and institutional affiliations.

Received: 4 March 2018 Accepted: 29 May 2018

Published online: 25 June 2018

\section{References}

1. Atlin GN, Cairns JE, Das B. Rapid breeding and varietal replacement are critical to adaptation of cropping systems in the developing world to climate change. Glob Food Secur. 2017;12:31-7.

2. Blazy J-M, Carpentier A, Thomas A. The willingness to adopt agro-ecological innovations: application of choice modelling to Caribbean banana planters. Ecol Econ. 2011;72:140-50.

3. Breustedt G, Müller-Scheeßel J, Latacz-Lohmann U. Forecasting the adoption of GM oilseed rape: evidence from a discrete choice experiment in Germany. J Agric Econ. 2008;59:237-56.

4. Byerlee D, Alex GE. Strengthening national agricultural research systems: policy issues and good practice, environmentally and socially sustainable development: rural development. Washington, DC: World Bank; 1998.

5. Cassman KG. Ecological intensification of cereal production systems: yield potential, soil quality, and precision agriculture. Proc Natl Acad Sci USA. 1999;96:5952-9.

6. Chandler RF. Rice in the tropics: a guide to the development of national programs. Los Baños: International Rice Research Institute; 1979.

7. Chebil A, Nasr H, Zaibet L. Factors affecting farmers' willingness to adopt salt-tolerant forage crops in south-eastern Tunisia. Afr J Agric Resour Econ. 2009:3:19-27.

8. Clancy D, Breen J, Moran B, Thorne F, Wallace M. Examining the socioeconomic factors affecting willingness to adopt bioenergy crops. J Int Farm Manag. 2011;5:25-40.

9. Cleveland DA. Is plant breeding science objective truth or social construction? The case of yield stability. Agric Hum Values. 2001;18:251-70.

10. Collard BCY, Beredo JC, Lenaerts B, Mendoza R, Santelices R, Lopena V, Verdeprado H, Raghavan C, Gregorio GB, Vial L, Demont M, Biswas PS, Iftekharuddaula KM, Rahman MA, Cobb JN, Islam MR. Revisiting rice breeding methods - evaluating the use of rapid generation advance (RGA) for routine rice breeding. Plant Prod Sci. 2017;20:337-52. https:// doi.org/10.1080/1343943X.2017.1391705.

11. Custodio MC, Demont M, Laborte A, Ynion J. Improving food security in Asia through consumer-focused rice breeding. Glob Food Secur. 2016;9:19-28.

12. De La Fuente GN, Frei UK, Lübberstedt T. Accelerating plant breeding. Trends Plant Sci. 2013;18:667-72.

13. England I, Stewart D, Walker S. Information technology adoption in health care: when organisations and technology collide. Aust Health Rev. 2000;23:176.

14. Evenson RE, Gollin D. Assessing the impact of the green revolution, 1960 to 2000. Science. 2003;300:758-62.

15. Fahim M, Dhanapala MP, Senadhira D, Lawrence MJ. Quantitative genetics of rice II. A comparison of the efficiency of four breeding methods. Field Crops Res. 1998:55:257-66.

16. Hall TJ, Dennis JH, Lopez RG, Marshall MI. Factors affecting growers' willingness to adopt sustainable floriculture practices. HortScience. 2009:44:1346-51.

17. Hargrove T. Rice breeders in Asia: a 10-country survey of their backgrounds, attitudes, and use of genetic materials, IRRI Research Paper Series No. 13, February 1978. International Rice Research Institute, Los Baños, Philippines; 1978.

18. Janwan M, Sreewongchai T, Scripichitt P. Rice breeding for high yield by advanced single seed descent. J Plant Sci. 2013;8:24-30.

19. Jennings PR, Coffman WR, Kauffman HE. Rice improvement. Los Baños: International Rice Research Institute; 1979. 
20. Khush GS. Green revolution: preparing for the 21st century. Genome. 1999;42:646-55.

21. Khush GS, Virk PS. IR varieties and their impact. Los Baños: International Rice Research Institute; 2005.

22. Knox J, Hess T, Daccache A, Wheeler T. Climate change impacts on crop productivity in Africa and South Asia. Environ Res Lett. 2012;7:034032.

23. Lenaerts B, De Mey Y, Demont M (2018) Global impact of accelerated plant breeding: evidence from a meta-analysis on rice breeding. PLoS One. https://doi.org/10.1371/journal.pone.0199016.

24. Maruyama K. Using rapid generation advance with single seed descent in rice breeding. Progress in irrigated rice research: selected papers and abstracts from the international rice research conference, 21-25 September 1987, Hangzhou, China. Los Baños: International Rice Research Institute; 1989. p. 253-9.

25. Mathijs E. Social capital and farmers' willingness to adopt countryside stewardship schemes. Outlook Agric. 2003;32:13-6.

26. Pandey S, Rajatasereekul S. Economics of plant breeding: the value of shorter breeding cycles for rice in Northeast Thailand. Field Crops Res. 1999;64:187-97.

27. Peng S, Huang J, Sheehy JE, Laza RC, Visperas RM, Zhong X, Centeno GS, Khush GS, Cassman KG. Rice yields decline with higher night temperature from global warming. Proc Natl Acad Sci USA. 2004;101:9971-5.
28. Poehlman JM, Sleper DA. Breeding field crops. 4th ed. Ames: Iowa State University Press; 1995.

29. Rogers EM. Diffusion of innovations. 5th ed. New York: Free Press, Simon and Schuster; 2003.

30. Rogers EM. Diffusion of innovations. 4th ed. New York: Free Press, Simon and Schuster; 1995.

31. Seck PA, Diagne A, Mohanty S, Wopereis MCS. Crops that feed the world 7: rice. Food Secur. 2012;4:7-24.

32. Sunding D, Zilberman D. The agricultural innovation process: research and technology adoption in a changing agricultural sector. In: Gardner BL, Rausser GC, editors. Handbook of agricultural economics, vol. 1A. Amsterdam: North Holland; 2001. p. 207-61.

33. Task Force on Higher Education and Society. Higher education in developing countries: peril and promise. Washington: World Bank; 2000.

34. Witcombe JR, Gyawali S, Subedi M, Virk DS, Joshi KD. Plant breeding can be made more efficient by having fewer, better crosses. BMC Plant Biol. 2013;13:22.
Ready to submit your research? Choose BMC and benefit from:

- fast, convenient online submission

- thorough peer review by experienced researchers in your field

- rapid publication on acceptance

- support for research data, including large and complex data types

- gold Open Access which fosters wider collaboration and increased citations

- maximum visibility for your research: over $100 \mathrm{M}$ website views per year

At BMC, research is always in progress.

Learn more biomedcentral.com/submissions 